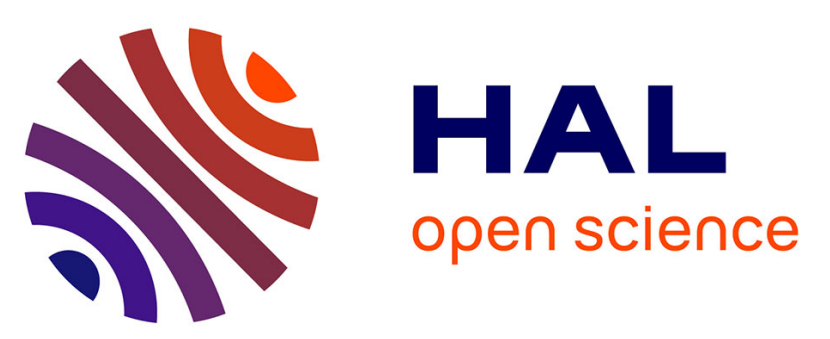

\title{
Educational level and family structure influence the dietary changes after the diagnosis of type 2 diabetes: evidence from the E3N study
}

Francesca Romana Mancini, Aurélie Affret, Courtney Dow, Beverley Balkau, Hélène Bihan, Françoise Clavel-Chapelon, Marie-Christine Boutron-Ruault, Fabrice Bonnet, Guy Fagherazzi

\section{To cite this version:}

Francesca Romana Mancini, Aurélie Affret, Courtney Dow, Beverley Balkau, Hélène Bihan, et al.. Educational level and family structure influence the dietary changes after the diagnosis of type 2 diabetes: evidence from the E3N study. Nutrition Research, 2017, 44, pp.9-17. 10.1016/j.nutres.2017.05.005 . hal-01596290

\section{HAL Id: hal-01596290}

https://hal-univ-rennes1.archives-ouvertes.fr/hal-01596290

Submitted on 13 Oct 2017

HAL is a multi-disciplinary open access archive for the deposit and dissemination of scientific research documents, whether they are published or not. The documents may come from teaching and research institutions in France or abroad, or from public or private research centers.
L'archive ouverte pluridisciplinaire HAL, est destinée au dépôt et à la diffusion de documents scientifiques de niveau recherche, publiés ou non, émanant des établissements d'enseignement et de recherche français ou étrangers, des laboratoires publics ou privés. 


\section{Educational level and family structure influence the dietary changes after the diagnosis of type 2 diabetes: evidence from the E3N study}

Francesca Romana Mancini, ${ }^{1,2,3} *$ Aurelie Affret, ${ }^{1,2,3} *$ Courtney Dow, ${ }^{1,2,3}$ Beverley Balkau, ${ }^{1,4}$ Hélène Bihan ${ }^{5}$, Françoise Clavel-Chapelon, ${ }^{1,2,3}$ Marie-Christine Boutron-Ruault, ${ }^{1,2,3}$ Fabrice Bonnet, ${ }^{1,2,6}$ Guy Fagherazzi $i^{1,2,3}$

1: INSERM U1018, Center for Research in Epidemiology and Population Health, Villejuif, France

2: University Paris-Saclay, University Paris-Sud, Villejuif, France

3: Gustave Roussy, F-94805, Villejuif, France

4: University Versailles, Saint Quentin, University Paris-Sud, Villejuif, France

5: Department of Endocrinology, Diabetology and Metabolic Diseases, Avicenne Hospital, Bobigny, France.

6: CHU Rennes, Université de Rennes 1, France

* FRM and AA have contributed equally to the study.

Corresponding author: Guy Fagherazzi, PhD

Inserm U1018, Centre for Research in Epidemiology and Population Health (CESP)

"Health across Generations" Team, Gustave Roussy, Espace Maurice Tubiana

114 rue Edouard Vaillant, 94805 Villejuif Cedex, France

Email: guy.FAGHERAZZI@gustaveroussy.fr

Tel :+33 1-42116140

Running title: Changes in diet after type 2 diabetes diagnosis.

Abbreviations: BMI, body mass index; E3N, epidemiologic prospective cohort study of women from the MGEN; FDep99, deprivation index in 1999; FFQ, food frequency questionnaire; INSEE, national institute of statistics and economic studies; MET, metabolic equivalent. 


\begin{abstract}
Type 2 diabetes (T2D) has no cure, but can be controlled by medication, diet and lifestyle changes. It has been suggested that diabetes dietary self-management is more difficult for people with socioeconomic difficulties. The objective of our study was to test the hypothesis that socioeconomic factors impact the change of diet after T2D diagnosis. The 57,304 French women included in the present study answered food frequency questionnaires (FFQ) in 1993 and 2005, questionnaires on socioeconomic factors, and were free from T2D in 1993. Between 1993 and 2005, 1,249 women developed T2D. Linear regression models evaluated whether having T2D diagnosed had an impact on energy and nutrient intakes and whether socioeconomic factors were implicated. T2D was associated with a reduction of energy $(\beta=-$ 74.70kcal/day, $p<0.001)$, carbohydrate $(\beta=-9.29 \mathrm{~g} /$ day, $\mathrm{p}<0.001)$, lipid $(\beta=-2.01 \mathrm{~g} /$ day, $\mathrm{p}<0.001)$ and alcohol $(\beta=-2.74 \mathrm{~g} / \mathrm{day}, \mathrm{p}=0.002)$ intakes, while there was no association with changes in protein or fiber intakes. The main socioeconomic factors that had an impact on dietary change were the level of education of T2D patients and whether or not they had a family (having a partner and/or children). The present study provides evidence that socioeconomic factors impact the way people with T2D change their dietary habits after diagnosis. Further; the family plays a crucial role in dietary self-management, probably encouraging T2D patients to follow dietary recommendations.
\end{abstract}

Keywords: Type 2 diabetes, socioeconomic factors, diet, food frequency questionnaires, E3N study. 


\section{Introduction}

In 2014,422 million adults worldwide (or $8.5 \%$ of the global population) had diabetes, compared with 108 million (4.7\%) in 1980, and it has been estimated that diabetes caused 1.5 million deaths in 2012 [1]. Diabetes can lead to serious complications and comorbidities that severely diminish the quality of life and ultimately lead to premature death [2]. Although it has no cure, diabetes can be controlled by medications along with an appropriate diet and lifestyle such as reducing energy intake, lowering carbohydrate intake, increasing fiber intake, reducing alcohol consumption, eating regular meals, maintaining a healthy weight, and engaging in physical activity [3, 4]. Nevertheless, people with diabetes may have difficulties in changing well-established habits, have a negative perception of the recommended regimen, encounter barriers related to social circumstances and to the practicalities of making lifestyle changes, and may lack the knowledge and understanding of the recommendations [5]. These barriers are usually greater in socioeconomically disadvantaged populations, in particular for changes in dietary habits [6]. Indeed several authors have reported that, in high-income countries, type 2 diabetes mellitus (T2D) mortality is higher in lower socioeconomic groups, as defined by the level of education, occupation, income, or the deprivation level of the area of residence [7-9].

The prevention of complications associated with diabetes is important as they are a burden on the health care system and are associated with higher mortality rates [10]. From a public health point of view, the overall objective is that T2D patients should self-manage their disease; however, not all people affected by T2D comply with medical recommendations $[11,12]$. Weaver et al. (2014) reported that changing the diet in T2D patients from low socioeconomic groups is challenged by limited access to healthy food, no household support for a healthy diet, financial restrictions, low motivation, and limited access to information 
about dietary management [6]. It is thus crucial to monitor if health policies that aim to improve the self-management of people with diabetes are actually effective.

The main objective of the study was to test the hypothesis that socioeconomic factors impact on the change of diet after T2D diagnosis, in the women participating in the prospective E3N (Etude Epidémiologique auprès des femmes de la Mutuelle Générale de l'Education Nationale) cohort study.

\section{Methods and materials}

\subsection{Study population}

E3N is a prospective cohort study initiated in 1990 and involving 98,995 women born in 1925-1950 and living in metropolitan France at inclusion [13]. E3N is the French part of the European Prospective Investigation into Cancer and Nutrition (EPIC), and the EPIC sub-study devoted to diabetes: Interaction of genetic and lifestyle factors on the incidence of type 2 diabetes (InterAct) [14]. In E3N, data are available from mailed questionnaires sent every 2-3 years, as well as from a drug-reimbursement claims database that has been available since 2004. The average follow-up per each questionnaire cycle has been $83 \%$, and to date, the overall loss to follow-up since 1990 has been 3\%. All women signed letters of informed consent, in compliance with the French National Commission for Computerized Data and Individual Freedom (CNIL).

The flow-chart in Figure 1 shows how the study population was selected. Briefly, from the 98,995 women in the cohort, we excluded women who had not completed the first food frequency questionnaire (FFQ) in 1993 and/or to the second FFQ in 2005 (n=38,614). Women with extreme values for the ratio between energy intake and required energy (below the 1st and above the 99th percentiles of the distribution in the population) $(\mathrm{n}=2188)$ and women with diabetes diagnosed before the first FFQ $(n=889)$ were also excluded. Our analysis 
included 57,304 women, among whom 1,249 had T2D diagnosed between the first and the second FFQ (group of interest), 12,713 did not have T2D but were validated incident cases of other major chronic diseases (OCD), such as cancer, cardiovascular disease, hypertension; finally 43,342 women were classed as healthy. The validation process for OCD cases has already been described [13].

\subsection{Ascertainment of Diabetes}

Within the E3N cohort, diabetes cases were validated using a specific algorithm in two steps. First, potential T2D cases were identified through self-reporting of diabetes, diabetes-specific diet, anti-diabetic drugs, or hospitalization for diabetes in any of the nine follow-up cohort questionnaires, or through the drug reimbursement file obtained from the insurance every three months since January 1st, 2004. All potential cases were then sent a detailed questionnaire that included questions on circumstances of diagnosis (year of diagnosis, symptoms, biological exams, fasting or random glucose concentrations at diagnosis), current diabetes therapy (recommendation of a medical diet or physical activity, glucose-lowering treatments), last measurement of fasting glucose and HbA1c levels. Cases were considered validated when positive for at least two of the following three sources: self-reported diabetes in the follow-up questionnaires and/or positive answer to the specific diabetes questionnaire (i.e. fasting plasma glucose $\geq 1.26 \mathrm{~g} / \mathrm{L}$ or random glucose $\geq 2.00 \mathrm{~g} / \mathrm{L}$ at diagnosis and/or current fasting plasma glucose $\geq 1.26 \mathrm{~g} / \mathrm{L}$ and/or current $\mathrm{HbA} 1 \mathrm{c} \geq 7 \%$ and/or reporting of glucose-lowering drug use) and/or glucose-lowering drugs reimbursed by the health insurance over the period $1 / 1 / 2004$ to $1 / 1 / 2012$. Women identified through the drug reimbursement file, but who were reimbursed for glucose-lowering drugs only once during the period and who had declared to be non-diabetic, were considered as non-cases. 


\subsection{Dietary data and socioeconomic factors}

Dietary data were collected in 1993 and in 2005 using a validated FFQ [15]. In the first FFQ, questions on 64 food groups, with 236 food items, were completed for 8 consumption occasions, from breakfast to after-dinner snacks (including the aperitif before lunch and dinner). In the second FFQ, 11 food groups were further subdivided into more specific food items and10 food groups were added (soya milk, soya yogurt, soya steak, dried fruit, infusions, chips, smoked fish, charcuterie, "mini-sausages" and meal substitutes), resulting in 290 food items. Conversion of foods into nutrients used a French food composition table compiled ad hoc for this study; it was derived from the major French food composition table (CIQUAL and updated version)[16], the McCance and Widdowson's food composition table [17] and several other published sources. Individual average daily dietary intakes of energy and nutrients (carbohydrates, proteins, dietary fiber, alcohol, and lipids) were estimated for the two FFQs.

Socioeconomic data collected in the E3N study included having or not a partner, level of education of the women and their partners, occupation, age at delivery of the first child, and number of children. Based on the women's professional activity, their salary was estimated from data provided by the French National Institute of Statistics and Economics Studies for

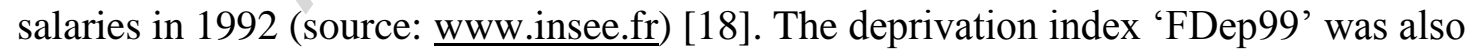
computed for each woman. This is based on the socio-economic level of their residential commune (the smallest administrative district in France), using four variables from the 1999 population census (source: www.insee.fr) and the tax authority's 2001 household income data (source: www.insee.fr): median household income, percentage of high school graduates in the population aged 15 years and older, percentage of blue-collar workers in the active population, and unemployment rate. The mean value of the FDep99 index in France is 0 and the more an area is deprived, the higher the FDep99 index [19]. 
Information on age, body mass index (BMI), level of physical activity and smoking status, were collected from the questionnaires and were used as covariates in the statistical analyses.

\subsection{Statistical analyses}

The average daily intakes of energy and nutrients are presented as medians (minimum, maximum) and they were compared for each FFQ, between the three health status groups (healthy, OCD, and T2D women) using the Kruskal Wallis test, and between FFQs within the same health status group using the Wilcoxon-Mann-Whitney test.

For each woman we calculated the difference in the daily intake of energy (kcal/day), carbohydrates (g/day), proteins (g/day), dietary fiber (g/day), alcohol (g/day), and lipids (g/day) between 1993 and 2005. Changes between the first and second FFQ are tabulated according to various strata.

Linear regression models estimated if being an incident case of T2D had an impact on the changes in energy and nutrient intakes between the two FFQs. Two dummy variables were created, one for the OCD group and one for the T2D group, and used in the models as independent variables, while the healthy group was used as the reference group. We first performed univariate analyses (Model 0), then we adjusted for age (years), BMI, physical activity (in metabolic equivalents, MET-hours/week), and smoking status (non-smoker, exsmoker, and current smoker) at baseline, and having a personal history of chronic disease (cancer, cardiovascular disease, or hypertension) before the first FFQ (Model 1). For variables with $<5 \%$ of values missing during follow-up, missing values were imputed with the median (quantitative variables) or the mode (qualitative variables) of the study population. In the case of $\geq 5 \%$ of missing values, a "missing" category was created.

In order to determine which socioeconomic variables had an impact on the changes in diet for incident T2D cases, we ran Model 1 including the investigated socioeconomic variables one- 
by-one, and an interaction term between the socioeconomic variable and the health status group (healthy subjects, OCD and T2D). Due to the fact that previous research has demonstrated that statistical power to detect interactions is lower than for main effects [2022], Model 1 was stratified on all socioeconomic factors for which the interaction term had a $\mathrm{P}$ value below 0.25 . Moreover, Model 3 was stratified also according to those variables considered crucial determinants of socioeconomic status [6-9], independently from the P value associated to the interaction [20-22].

All statistical analyses used SAS 9.4 software (SAS Institute Inc.). For all statistical analysis significance was set at $\mathrm{P}<0.05$.

\section{Results}

\subsection{Baseline Characteristics}

The main characteristics of the study population are summarized in Table 1, according to the health status. Women with incident T2D $(n=1,249)$ were older, had a higher BMI, and reported lower physical activity than women from the healthy or the OCD group. Moreover, those diagnosed with T2D reported more frequently, a personal history of cardiovascular disease or hypertension before the first FFQ.

\subsection{Estimated daily intakes by health status groups}

Between 1993 and 2005, the healthy group increased significantly their intakes of energy and all nutrients, with the exception of proteins, which decreased. For the OCD group, energy intake, carbohydrates, and dietary fiber intakes increased, protein decreased and there was no change in alcohol or lipid intake. In contrast, for the T2D group, alcohol and lipid intakes were lower in the second FFQ compared with the first one, while no difference was found for energy intake. As for the healthy and OCD groups, the T2D group reported a lower intake of 
protein and a higher intake of carbohydrates in the second compared to the first FFQ

(Table 2).

When comparing intakes reported by the three health status groups in 1993 (first FFQ), the group with later incident T2D had significantly higher intakes of energy, proteins and lipids compared to those reported from the healthy and OCD groups, while no difference was found for carbohydrates, dietary fiber, or alcohol intake. For the second FFQ (in 2005) women in the T2D group reported higher intakes of proteins and lower intakes of carbohydrates and alcohol compared with the healthy and OCD groups. There were no differences between the reported intakes of energy, dietary fiber and lipids between the three health status groups at the second FFQ (Table 2).

\subsection{Impact of $T 2 D$ diagnosis on dietary changes}

Because results obtained with both the univariate (Model 0) and multivariable (Model 1) linear regression models did not substantially change, only the results from the latter model will be commented. As reported in Table 3, diagnosis of T2D was associated with a decrease of energy, carbohydrates, lipids, and alcohol intakes, while no variation was observed with proteins and fiber intake.

\subsection{Interaction terms between socioeconomic variables and T2D}

We calculated interaction terms between socioeconomic variables and T2D. The socioeconomic factors that had an impact on the diet changes in incident T2D cases were "not having children/having at least one child", independently of the "age at delivery", and "having/not having a partner", independently from the education level of the partner. Indeed these last two variables were the only two, among all the socioeconomic variables included in this study, for which the interaction term had a $P$-value below 0.25 . Therefore, the variable "having/not having children" and the variable "having/not having a partner" were merged into 
a third variable "having/not having a family" (where "not having a family" included women without a partner and without children). Model 1 was then stratified on this last variable (Table 3).

\subsection{Impact of T2D diagnosis on dietary changes analyzed separately for each} socioeconomic factor

\subsubsection{Family}

As reported in table 3, for the women with incident T2D, those with a family decreased their intakes of energy $(\beta=-84.31 \mathrm{kcal} / \mathrm{day}, P<0.001)$, carbohydrates $(\beta=-10.21 \mathrm{~g} / \mathrm{day}, P<0.001)$, alcohol $(\beta=-2.12 \mathrm{~g} / \mathrm{day}, P<0.001)$, and lipids $(\beta=-3.20 \mathrm{~g} / \mathrm{day}, P=0.001)$ while women without a family, only their fiber intake was increased $(\beta=2.53 \mathrm{~g} / \mathrm{day}, P=0.01)$. There was no variation in protein intake for either of the two groups.

\subsubsection{Education Level}

Due to the fact that the education level is a crucial determinant of socioeconomic status, by default we stratified on the level of education, independently from the $\mathrm{P}$ value of the interaction term. When stratifying according to the education level, for women that did not achieve a high school diploma, there no changes in diet were observed. For women with an education level between high school and a two-year university diploma, there were decreased intakes of energy $(\beta=-85.57 \mathrm{kcal} / \mathrm{day}, P=0.001)$, carbohydrates $(\beta=-12.17 \mathrm{~g} / \mathrm{day}, P<0.001)$, alcohol $(\beta=-1.82 \mathrm{~g} / \mathrm{day} ; P<0.001)$, and lipids $(\beta=-3.20 \mathrm{~g} /$ day; $P=0.011)$. Similar associations were seen for women with an education level above a two-year university diploma, except for changes in carbohydrate intake (Table 3).

\subsubsection{Deprivation index of the area of residence}

As for the education level, by default we performed the analysis stratified according to the deprivation index of the area of residence, independently from the $\mathrm{P}$ value of the interaction 
term. When dividing the study population into two groups according to the deprivation index of the area of residence (FDep99 above or below 0), there was a decrease in intakes of energy $(\beta=-60.62 \mathrm{kcal} /$ day, $P=0.032$ in less deprived areas; $\beta=-87.80 \mathrm{kcal} / \mathrm{day}, P=0.001$ in more deprived areas), carbohydrates $(\beta=-7.76 \mathrm{~g} / \mathrm{day}, \mathrm{p}=0.029$ and $\beta=-10.61 \mathrm{~g} / \mathrm{day}, P=0.002$ in less and more deprived areas, respectively) and alcohol $(\beta=-1.94 \mathrm{~g} / \mathrm{day}, P<0.001$ and $\beta=-2.07$ g/day, $P<0.001$ in less and more deprived areas, respectively) in both strata. No association was observed for changes in protein and fiber intakes. Finally, there was a decrease in lipid intake only in women living in more deprived areas $(\beta=-3.38 \mathrm{~g} / \mathrm{day}, P<0.007)$ (Table 3).

\subsection{Impact of T2D diagnosis on dietary changes in different socioeconomic groups}

Model 1 was simultaneously stratified for the level of education, FDep99 index, and family status (Table 4). For women who did not have a high school diploma, incident T2D had no impact on changes in the diet, independently of the FDep99 index and having or not a family. For women with an education level between high school and a two-year university diploma, T2D was associated with a decrease in energy intake $(\beta=-88.5 \mathrm{kcal} / \mathrm{day}, P=0.035$ and $\beta=-85.8$ $\mathrm{kcal} / \mathrm{day}, P=0.017$ in less and more deprived areas, respectively ), carbohydrates $(\beta=-37.7$ $\mathrm{g} / \mathrm{day}, P=0.009$ in less deprived areas; $\beta=-11.2 \mathrm{~g} / \mathrm{day}, P=0.014$ in more deprived areas), and alcohol $(\beta=-2.4 \mathrm{~g} / \mathrm{day}, P=0.003$ and; $\beta=-1.7 \mathrm{~g} /$ day, $P=0.010$ in less and more deprived areas, respectively) exclusively in women with a family, independently from the FDep99 index, while T2D was associated with a decrease in lipid intake, but only in women with a family and living in more deprived areas $(\beta=-3.5 \mathrm{~g} / \mathrm{day}, P=0.037)$. Finally for women with an education level above a two-year university diploma, there was a decrease in energy intake ( $\beta=-202.3 \mathrm{kcal} /$ day, $P=0.001)$, carbohydrates $(\beta=-20.4 \mathrm{~g} /$ day, $P=0.006)$, proteins $(\beta=-5.0$ g/day, $\mathrm{p}=0.05)$, alcohol $(\beta=-4.4 \mathrm{~g} / \mathrm{day}, \mathrm{p}<0.001)$, and lipids $(\beta=-7.8 \mathrm{~g} / \mathrm{day}, \mathrm{p}<0.005)$ in women with a family and living in more deprived areas. An increase in protein and fiber intake was 
seen for the women with an education level above a two-year university diploma, no family and living in less deprived areas (respectively $\beta=13.5 \mathrm{~g} / \mathrm{day}, P=0.02 ; \beta=6.4 \mathrm{~g} / \mathrm{day}, P=0.001$ ).

\section{Discussion}

In the large E3N cohort, our study investigated if women's dietary habits changed after a diagnosis of T2D and whether socioeconomic factors have an impact on these changes.

Our results show that energy and all nutrient intakes, with the exception of protein intake, increased in the general healthy population, as well as in women with incident chronic diseases other thanT2D, in a time span of 12 years between 1993 and 2005. This increase is likely due to changes in the population's dietary habits during the last decades [23-26], but could also be explained in part by the fact that in the second FFQ, specific questions on 54 specific food items were added. In contrast, for women with an incident T2D, the overall intake of energy and all nutrients decreased or at least any increase was less pronounced.

The global multivariable linear regression models highlight that women with a T2D diagnosis had a decrease of energy, carbohydrates, lipids, and alcohol intakes. These results are in line with the dietary recommendations provided to people with T2D [7, 8], although no significant increase in fiber intake was observed. Our results show that protein intake did not change after T2D diagnosis; this probably reflects the contradictory recommendations provided with regard to the protein intake for people with T2D [27-29].

Our study highlights how having a family and the education level impact on women's capacity to change their diet after T2D diagnosis. In particular, women with middle or high education levels and those with a family reduced their intakes of energy, carbohydrates, lipids, and alcohol after T2D diagnosis. The deprivation level of the area of residence did not seem relevant with regard to diet changes, except for women with a high education level and 
with a family, who decreased energy, carbohydrates, proteins, and lipids only when living in more deprived areas.

The level of education appears to be the most important socioeconomic factor, but not the only one, to impact on the capacity to change the diet after T2D diagnosis. Considering that the education level is a reliable proxy of the socioeconomic group, there is a need to address health interventions specifically for the lower socioeconomic groups who have a poor health literacy, which is an important barrier to chronic-disease care [30]. Moreover, our results confirm what has already been suggested by other authors: the family plays a crucial role in diabetes self-management, in particular regarding following dietary recommendations. It is plausible that, in women from the middle and high socioeconomic groups, the family context offers encouragement to follow dietary recommendations and dissuades them from unhealthy behaviors. In contrast, it has been pointed out by other authors how low socioeconomic group families often undermine the capacity of T2D patients to follow a healthy diet and this condition is probably reflected in our results $[12,31]$.

We are aware of some limitations of our study. Although the household income is an important variable when defining socioeconomic status; we could not include the women's salary in our analysis as there was a high percentage of missing values, and data on the overall household income were not available. Using only the women's salary as a proxy of the overall household income, could introduce a consistent bias in the analysis. But, since we considered other variables strongly correlated with income, we are confident that information concerning the household income would not change the results. Moreover, the two FFQ used in the present study had some differences due to the fact that some questions on individual food items were added in the second FFQ. It has been reported by previous authors that food questionnaires including more food items are more likely to result in greater calculated intake simply due to the available questions [32]. However, this should not affect the overall 
reliability of our results: indeed women in the three health groups in the present study answered the same FFQs, so any potential bias in the intake measurements is equally present in all groups, leading to a non-differential measurement bias.

Finally, other confounders may remain unmeasured in our study, even though we included most of the known and potential variables that may have an impact on a woman's capacity to modify her diet after T2D diagnosis.

Our study has several strengths. To our knowledge this is the first large study investigating the dietary changes adopted by people after diagnosis of T2D over a 12- year period. We combined dietary information provided by extensive FFQs with data on a number of socioeconomic factors providing a comprehensive picture of the capacities of T2D patients to follow the dietary recommendations necessary to reduce the risk of complications or premature death. Finally our study included a large number of T2D cases so the statistical power was high in our analyses.

The present study provides evidence that socioeconomic factors impact the way T2D patients change their dietary habits after diagnosis. In particular, our study highlights how, besides the educational level, the family plays a crucial role in dietary self-management, probably encouraging T2D patients to follow dietary recommendations. It is therefore important to provide better health interventions focused on socio-economically disadvantaged groups and those that do not have a family. 


\section{Acknowledgment}

The authors are indebted to all participants for their continued participation and to all members of the $\mathrm{E} 3 \mathrm{~N}$ study group. The $\mathrm{E} 3 \mathrm{~N}$ cohort is being carried out with the financial support of the "'Mutuelle Générale de l'Education Nationale”(MGEN); European Community; French League against Cancer (LNCC); Gustave Roussy (GR); French Institute of Health and Medical Research (Inserm). This present work was supported by a grant from the World Cancer Research Fund (WCRF). The validation of potential diabetes cases was supported by the European Union (Integrated Project LSHM-CT-2006-037197 in the 6th European Community Framework Programme) InterAct project. The authors have no conflicts of interest to declare. FRM and AA have contributed equally to the study and should be considered both as first authors. FRM, AA and GF conceived and designed the study. FCC collected the data. FRM and AA performed the statistical analysis. FRM, AA and FG drafted the original manuscript. All authors contributed to the interpretation of data discussed in the manuscript, revised the manuscript and approved its final version. FG is the guarantor of this work and, as such, had full access to all the data in the study and takes responsibility for the integrity of the data and the accuracy of the data analysis. 


\section{Bibliography}

[1] World Health Organization (WHO). Global report on diabetes. WHO Library

Cataloguing-in-Publication Data. Geneva: World Health Organization; 2016. ISBN 978 9241565257

[2] Deshpande AD, Harris-Hayes M, Schootman M. Epidemiology of diabetes and diabetesrelated complications. Phys Ther. 2008 Nov;88(11):1254-64.

[3] American Diabetes Association. Economic costs of diabetes in the U.S. In 2007. Diabetes Care. 2008 Mar; 31(3):596-615. Erratum in: Diabetes Care. 2008 Jun;31(6):1271.

[4] Park K. Trends in adherence to dietary recommendations among Korean type 2 diabetes mellitus patients. Nutr Res Pract. 2015 Dec;9(6):658-66.

[5] Booth AO, Lowis C, Dean M, Hunter SJ, McKinley MC. Diet and physical activity in the self-management of type 2 diabetes: barriers and facilitators identified by patients and health professionals. Prim Health Care Res Dev. 2013 Jul;14(3):293-306.

[6] Weaver RR, Lemonde M, Payman N, Goodman WM. Health capabilities and diabetes self-management: the impact of economic, social, and cultural resources. Soc Sci Med. 2014 Feb;102:58-68.

[7] Connolly V, Unwin N, Sherriff P, Bilous R, Kelly W. Diabetes prevalence and socioeconomic status: a population based study showing increased prevalence of type 2 diabetes mellitus in deprived areas. J Epidemiol Community Health. 2000 Mar;54(3):1737.

[8] Espelt A, Borrell C, Roskam AJ, Rodríguez-Sanz M, Stirbu I, Dalmau-Bueno A, Regidor E, Bopp M, Martikainen P, Leinsalu M, Artnik B, Rychtarikova J, Kalediene R, Dzurova 
D, Mackenbach J, Kunst AE. Socioeconomic inequalities in diabetes mellitus across Europe at the beginning of the 21st century. Diabetologia. 2008 Nov;51(11):1971-9.

[9] Agardh E, Allebeck P, Hallqvist J, Moradi T, Sidorchuk A. Type 2 diabetes incidence and socio-economic position: a systematic review and meta-analysis. Int J Epidemiol. 2011 Jun;40(3):804-18. doi: 10.1093/ije/dyr029.

[10] Franz MJ, Bantle JP, Beebe CA, Brunzell JD, Chiasson JL, Garg A, Holzmeister LA, Hoogwerf B, Mayer-Davis E, Mooradian AD, Purnell JQ, Wheeler M. Evidence-based nutrition principles and recommendations for the treatment and prevention of diabetes and related complications. Diabetes Care. 2002 Jan;25(1):148-98.

[11] Thanopoulou A, Karamanos B, Angelico F, Assaad-Khalil S, Barbato A, Del Ben M, Djordjevic P, Dimitrijevic-Sreckovic V, Gallotti C, Katsilambros N,Migdalis I, Mrabet M, Petkova M, Roussi D, Tenconi MT. Nutritional habits of subjects with Type 2 diabetes mellitus in the Mediterranean Basin: comparison with thenon-diabetic population and the dietary recommendations. Multi-Centre Study of the Mediterranean Group for the Study of Diabetes (MGSD). Diabetologia. 2004 Mar;47(3):367-76.

[12] Aljasem LI, Peyrot M, Wissow L, Rubin RR. The impact of barriers and self-efficacy on self-care behaviors in type 2 diabetes. Diabetes Educ. 2001 May-Jun;27(3):393-404.

[13] Clavel-Chapelon F; E3N Study Group. Cohort Profile: The French E3N Cohort Study. Int J Epidemiol. 2015 Jun;44(3):801-9.

[14] Langenberg C, Sharp SJ, Franks PW, Scott RA, Deloukas P, Forouhi NG, Froguel P, Groop LC, Hansen T, Palla L et al. Gene-lifestyle interaction and type 2 diabetes: the EPIC InterAct case-cohort study. PLoS Med 2014, 11:e1001647 
[15] van Liere MJ, Lucas F, Clavel F, Slimani N, Villeminot S. Relative validity and reproducibility of a French dietary history questionnaire. Int J Epidemiol. 1997;26 Suppl 1:S128-36.

[16] Favier J.C., Ireland-Ripert J., Toque C. , Feinberg M. Répertoire général des aliments. Table de composition (Food composition table) CIQUAL-REGAL (French). INRA; AFSSA; CIQUAL; TEC \& DOC, (1995).

[17] Paul AA, Southgate DAT. McCance \& Widdowson's the Food Composition of Foods. Amsterdam, New York, Oxford: Elsevier, North-Holland, Biomedia Press; 1976. 4th Edition MRC Special Report No. 297.

[18] Institut National de la Statistique et des Etudes Economiques (INSEE). http://www.insee.fr/. (Accessed 24 Feb 2016).

[19] Rey G, Jougla E, Fouillet A, Hemon D. Ecological association between a deprivation index and mortality in France over the period 1. BMC Public Health. 2009;9:33

[20] Durand CP. Does raising type 1 error rate improve power to detect interactions in linear regression models? A simulation study. PLoS One. 2013 Aug 16;8(8):e71079

[21] Selvin S: Statistical Analysis of Epidemiologic Data New York: NY: Oxford University Press; 1996:213-214.

[22] Marshall S (2007) Power for tests of interaction: Effect of raising the type I error rate. Epidemiol Perspect Innov 4: 4

[23] Joint WHO/FAO Expert Consultation on Diet, Nutrition and the Prevention of Chronic Diseases. Diet, nutrition and the prevention of chronic diseases: report of a joint 
WHO/FAO expert consultation, Geneva, 28 January -- 1 February 2002. WHO technical report series; 916. ISBN 924120916 X (NLM classification: QU 145) ISSN 0512-3054

[24] Nielsen SJ, Popkin BM. Changes in beverage intake between 1977 and 2001. Am J Prev Med. 2004 Oct;27(3):205-10.

[25] Poti JM, Popkin BM. Trends in energy intake among US children by eating location and food source, 1977-2006. J Am Diet Assoc. 2011 Aug;111(8):1156-64.

[26] Briefel RR, Johnson CL. Secular trends in dietary intake in the United States. Annu Rev Nutr. 2004;24:401-31.

[27] Hamdy O, Horton ES. Protein content in diabetes nutrition plan. Curr Diab Rep. 2011 Apr;11(2):111-9.

[28] Linn T, Geyer R, Prassek S, Laube H. Effect of dietary protein intake on insulin secretion and glucose metabolism in insulin-dependent diabetes mellitus. J Clin Endocrinol Metab. 1996 Nov;81(11):3938-43.

[29] Gannon MC, Nuttall FQ, Saeed A, Jordan K, Hoover H. An increase in dietary protein improves the blood glucose response in persons with type 2 diabetes. Am J Clin Nutr. 2003 Oct;78(4):734-41.

[30] Schillinger, Association of Health Literacy With Diabetes Outcomes JAMA. $2002 ; 288(4): 475-482$.

[31] Ramal E, Petersen AB, Ingram KM, Champlin AM. Factors that influence diabetes selfmanagement in Hispanics living in low socioeconomic neighborhoods in San Bernardino, California. J Immigr Minor Health. 2012 Dec;14(6):1090-6. 
[32] Cade JE1, Burley VJ, Warm DL, Thompson RL, Margetts BM. Food-frequency questionnaires: a review of their design, validation and utilisation. Nutr Res Rev. 2004 Jun;17(1):5-22. 
Table 1. Study population characteristics, stratified by health status. The E3N Study ( $n=57304)$.

\begin{tabular}{|c|c|c|c|c|}
\hline Variable & & Healthy (N=43342) & $\begin{array}{l}\text { Health status groups } \\
\text { Other chronic diseases } \\
(\mathrm{N}=12713)\end{array}$ & $\begin{array}{l}\text { Type } 2 \text { diabetes } \\
(\mathrm{N}=1249)\end{array}$ \\
\hline & & \multicolumn{3}{|c|}{ Means (SD) } \\
\hline Age (years) & & $52.3(6.4)$ & $53.1(6.5)$ & $54.2(6.5)$ \\
\hline BMI $\left(\mathrm{kg} / \mathrm{m}^{2}\right)$ & & $22.6(3.0)$ & $23.1(3.2)$ & $26.9(4.8)$ \\
\hline $\begin{array}{c}\text { Physical activity } \\
\text { (Met-h/week) }^{1}\end{array}$ & & $46.2(49.7)$ & $45.9(45.0)$ & $45.7(47.1)$ \\
\hline $\begin{array}{c}\text { Prevalent cancer before } \\
\text { the first FFQ }\end{array}$ & & $696(1.61)$ & $126(0.99)$ & $24(1.92)$ \\
\hline $\begin{array}{c}\text { Prevalent hypertension } \\
\text { before the first FFQ }\end{array}$ & & $17173(39.62)$ & 2617 (20.59) & $724(57.97)$ \\
\hline $\begin{array}{c}\text { Prevalent } \mathrm{CVD}^{2} \text { before } \\
\text { the first FFQ }\end{array}$ & & $1996(4.61)$ & $799(6.28)$ & $108(8.65)$ \\
\hline Smokes & & $5512(12.72)$ & $1631(12.83)$ & $162(12.97)$ \\
\hline $\begin{array}{c}\text { Deprivation index } \\
\text { (FDepp99) }<0\end{array}$ & & $22620(52.2)$ & $6668(52.5)$ & $583(46.7)$ \\
\hline \multirow[t]{2}{*}{$\begin{array}{c}\text { Age at first birth } \\
\text { (years) }\end{array}$} & & $24.9(3.9)$ & $25.0(4.0)$ & $24.7(4.1)$ \\
\hline & & + & $\mathbf{N}(\%)$ & \\
\hline \multirow{3}{*}{ Education level } & $<$ high school diploma & $5785(13.35)$ & $1836(14.44)$ & $248(19.86)$ \\
\hline & $\begin{array}{l}\text { high school diploma - } \\
\text { two-year university }\end{array}$ & $21523(49.66)$ & $6419(50.49)$ & $659(52.76)$ \\
\hline & $\begin{array}{c}\text { >two-year university } \\
\text { diploma }\end{array}$ & 16034 (36.99) & $4458(35.07)$ & $342(27.38)$ \\
\hline \multirow{4}{*}{ Number of children } & none & $4977(11.48)$ & $1440(11.33)$ & $143(11.45)$ \\
\hline & 1 child & $6685(15.42)$ & $1882(14.8)$ & $183(14.65)$ \\
\hline & 2 children & $19189(44.27)$ & $5648(44.43)$ & $497(39.79)$ \\
\hline & more than 2 children & $12491(28.82)$ & $3743(29.44)$ & $426(34.11)$ \\
\hline \multirow{4}{*}{$\begin{array}{c}\text { Education level of the } \\
\text { partner }\end{array}$} & $<$ high school diploma & $12230(28.22)$ & $3588(28.22)$ & 437 (34.99) \\
\hline & $\begin{array}{l}\text { high school diploma - } \\
\text { two-year university }\end{array}$ & $11868(27.38)$ & $3452(27.15)$ & $329(26.34)$ \\
\hline & $\begin{array}{c}\text { >two-year university } \\
\text { diploma }\end{array}$ & $14589(33.66)$ & $4223(33.22)$ & $319(25.54)$ \\
\hline & No partner & $4655(10.74)$ & $1450(11.41)$ & $164(13.13)$ \\
\hline \multirow{5}{*}{$\begin{array}{l}\text { Women's salary } \\
\text { (francs) }\end{array}$} & $<111270$ & $4362(10.06)$ & $1315(10.34)$ & $143(11.45)$ \\
\hline & from 111270 to 116190 & $12176(28.09)$ & $3605(28.36)$ & $378(30.26)$ \\
\hline & m 1161890 to 158450 & $8616(19.88)$ & $2555(20.1)$ & $252(20.18)$ \\
\hline & $>158450$ & $12764(29.45)$ & $3558(27.99)$ & $293(23.46)$ \\
\hline & info missing & $5424(12.51)$ & $1680(13.21)$ & $183(14.65)$ \\
\hline
\end{tabular}

${ }^{1}$ MET: Metabolic Equivalent of Task; ${ }^{2}$ CVD: Cardio Vascular Disease 
Table 2. Intake of energy and the main nutrients reported in the first and second Food Frequency Questionnaires (FFQ) stratified by health group. The E3N Study ( $\mathrm{n}=57304)$.

\begin{tabular}{|c|c|c|c|c|}
\hline & \multicolumn{4}{|c|}{ Health groups } \\
\hline & \multirow{2}{*}{$\frac{\text { Healthy }}{\text { Median (min-max) }}$} & \multirow{2}{*}{$\begin{array}{c}\text { Other chronic diseases } \\
\text { Median (min-max) } \\
\end{array}$} & \multicolumn{2}{|l|}{ Type 2 diabetes } \\
\hline & & & Median (min-max) & $P$ value** \\
\hline FFQ1 : Energy (kcal/day) & $2157.9(816.1-4887.6)$ & $2159.9(892.2-4553.6)$ & $2231.5(990.2-4403.3)$ & 0.0004 \\
\hline FFQ2 : Energy (kcal/day) & $2227.4(669.5-5890.9)$ & $2224.2(716.7-5911.5)$ & $2226.9(773.2-5512.3)$ & 0.5497 \\
\hline$P$ value* & $<0.0001$ & $<0.0001$ & 0.7788 & \\
\hline $\begin{array}{c}\text { FFQ1 : Carbohydrates } \\
\text { (g/day) }\end{array}$ & $229.1(37.9-625.2)$ & $229.6(40.5-592.6)$ & $229.9(82.9-594.6)$ & 0.5810 \\
\hline $\begin{array}{c}\text { FFQ2 : Carbohydrates } \\
\text { (g/day) }\end{array}$ & $248.1(28.4-717.4)$ & $248.3(31.6-693.2)$ & $242.2(78.6-663.5)$ & $<.0001$ \\
\hline$P$ value* & $<0.0001$ & $<0.0001$ & $<0.0001$ & \\
\hline FFQ1 : Protein (g/day) & $95.1(22.8-230.8)$ & $95.8(24.8-238.8)$ & $101.9(41.0-228.9)$ & $<0.0001$ \\
\hline FFQ2 : Protein (g/day) & $91.1(14.9-310.1)$ & $91.6(13.0-302.8)$ & $97.4(21.2-279.7)$ & $<0.0001$ \\
\hline$P$ value* & $<0.0001$ & $<0.0001$ & 0.0013 & \\
\hline FFQ1 : Fibre (g/day) & $24.2(2.9-85.4)$ & $24.1(4.0-69.6)$ & $24.5(5.6-55.6)$ & 0.0870 \\
\hline FFQ2 : Fibre (g/day) & $26.3(3.4-120.4)$ & $26.4(2.5-87.8)$ & $26.6(6.3-74.8)$ & 0.2670 \\
\hline$P$ value* & $<0.0001$ & $<0.0001$ & 0.0002 & \\
\hline FFQ1 : Alcohol (g/day) & $6.8(0.0-143.5)$ & $6.9(0.0-140.7)$ & $6.5(0.0-113.5)$ & 0.4446 \\
\hline FFQ2 : Alcohol (g/day) & $7.4(0.0-191.6)$ & $7.1(0.0-191.3)$ & $4.9(0.0-111.4)$ & $<.0001$ \\
\hline$P$ value* & $<0.0001$ & 0.6562 & 0.0004 & \\
\hline FFQ1 : Lipids (g/day) & $85.7(23.5-259.6)$ & $85.6(22.4-228.2)$ & $89.9(27.4-213.0)$ & $<.0001$ \\
\hline FFQ2 : Lipids (g/day) & $86.3(13.1-322.5)$ & $85.4(10.8-286.1)$ & $87.0(23.9-261.9)$ & 0.3002 \\
\hline$P$ value* & 0.0095 & 0.6105 & 0.0042 & \\
\hline
\end{tabular}

* Wilcoxon-Mann-Whitney test

** Krsukal-Wallis test 
Table 3. Associations between the differences in daily intake reported in the first and second Food Frequency Questionnaires $(\Delta)$ of energy and nutrients and type 2 diabetes and stratified by socioeconomic factors individually. The E3N Study ( $\mathrm{n}=57304)$.

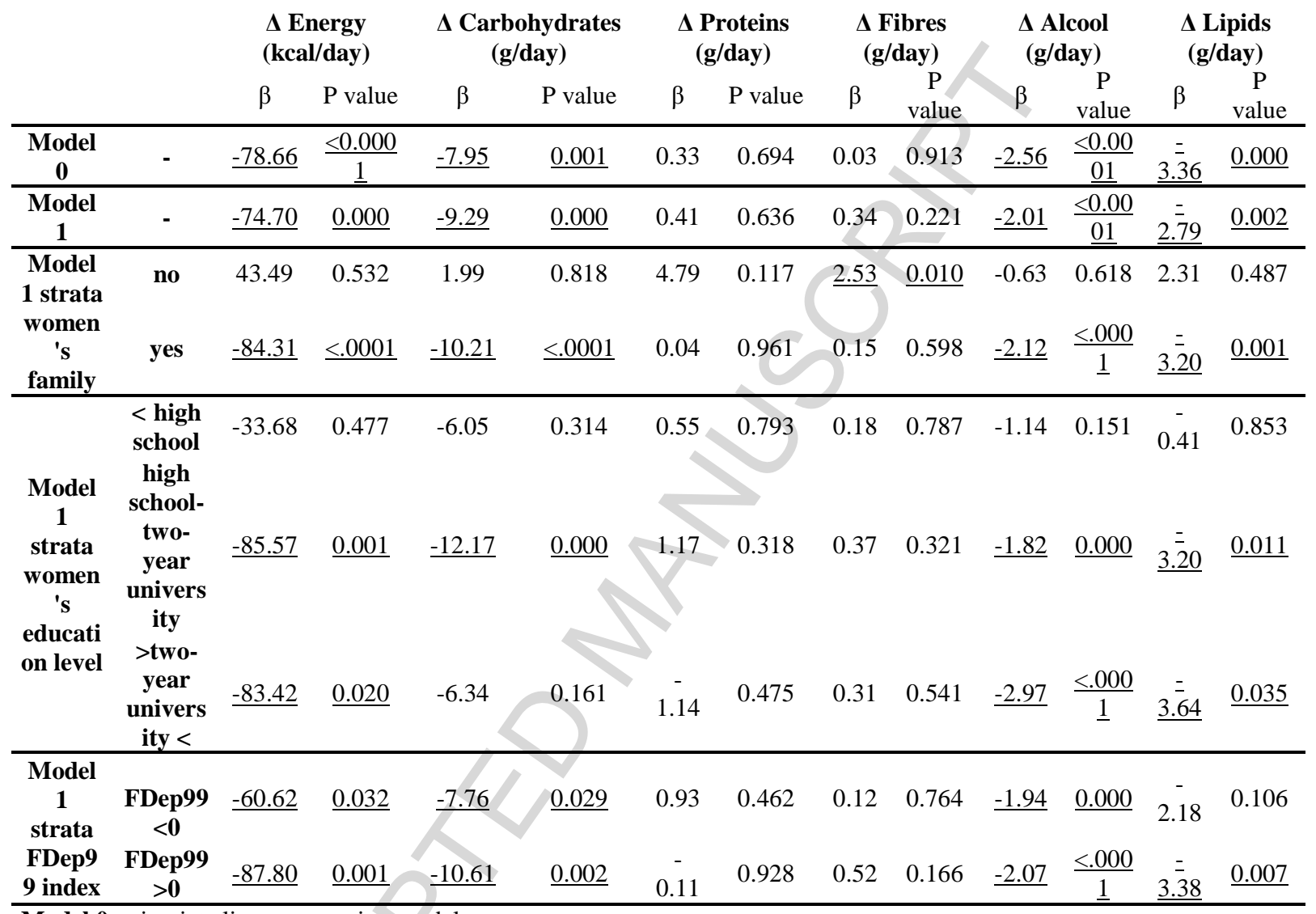

Model 0 univariate linear regression model;

Model 1 multivariable linear regression model adjusted for age, body mass index (BMI), physical activity (in metabolic equivalents, MET-hours/week) and smoking status (non-smoker, ex-smoker and currant smoker) at baseline and having a personal history of chronic disease (cancer, cardiovascular disease or hypertension) before the first FFQ. 
Table 4. Relations between the changes in daily intake reported in the first and second Food Frequency Questionnaires $(\Delta)$ of energy and nutrients and type 2 diabetes stratified by socioeconomic factors simultaneously. The E3N Study ( $\mathrm{n}=57304)$.

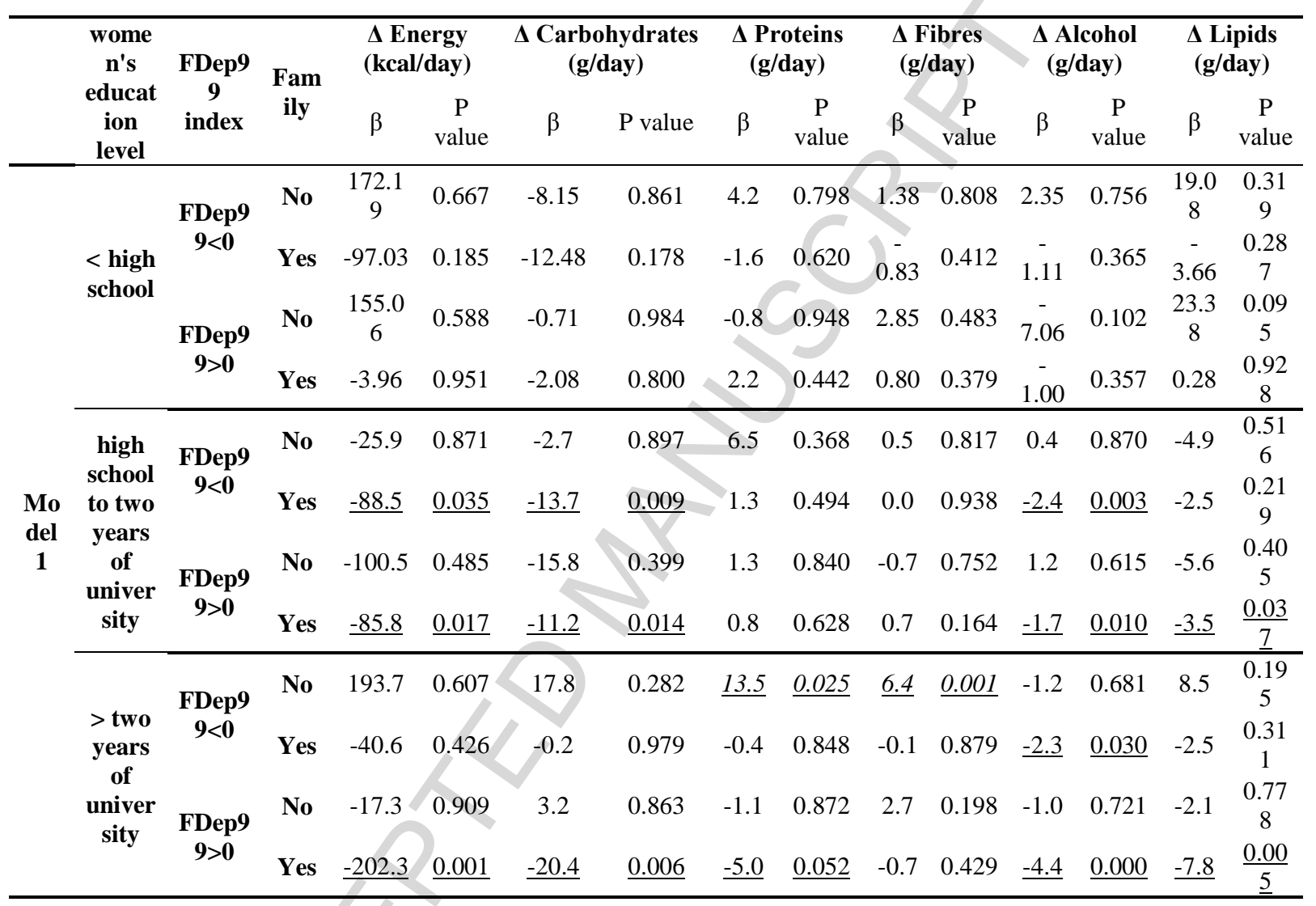

Model 1 multivariable linear regression model adjusted for age, body mass index (BMI), physical activity (in metabolic equivalents, MET-hours/week) and smoking status (non-smoker, ex-smoker and currant smoker) at baseline and having a personal history of chronic disease (cancer, cardiovascular disease or hypertension) before the first FFQ 
Figure1: Flowchart illustrating the selection process of the study population. The E3N Study.

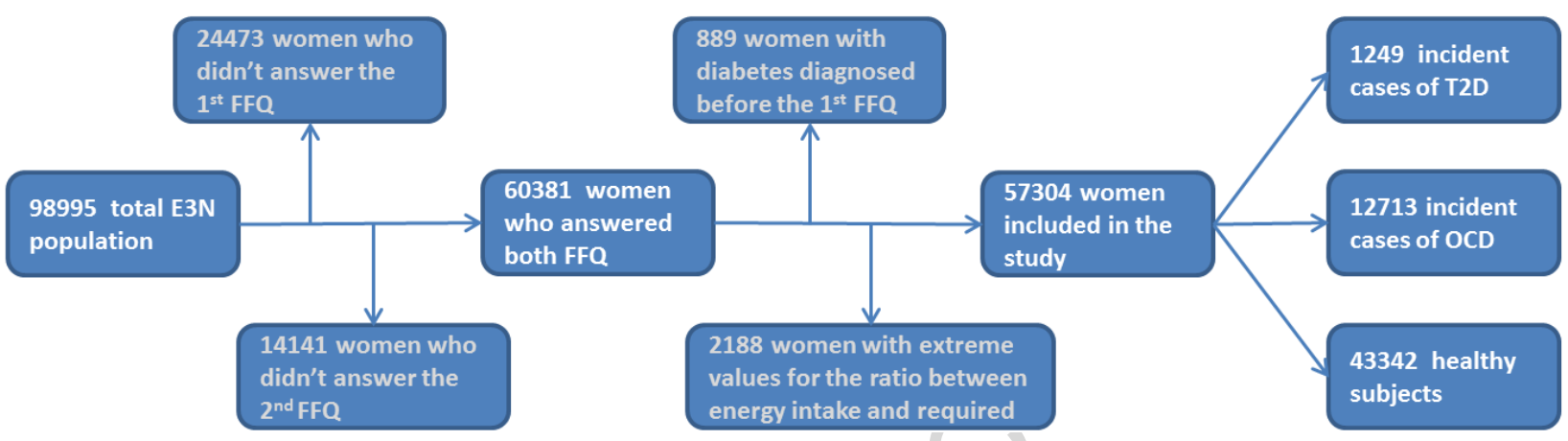

FFQ: food frequency questionnaire;

T2D: Type 2 diabetes;

OCD: other major chronic diseases such as such as cancer, cardiovascular disease, and hypertension 